EXERCISE PROGRAMMES - THE EUROPEAN EXPERIENCE

\author{
M. CARRUTHERS, MD, MRCPath, MRCGP \\ Director of Clinical Laboratory Services, \\ The Maudsley Hospital, Denmark Hill, London SE5 $8 A Z$.
}

One way of looking at exercise programmes is in terms of the seven ages of exercising man.

\section{THE BABY}

Firstly the baby is likely to be a better co-ordinated athlete, and a less anxious competitor if childbirth is made as far as possible neither physically nor mentally traumatic, and good maternal contact is maintained by breast feeding. Many of the children born by the gentle technique described by the French Obstetrician Leboyer (1974) are said to be ambidextrous, well co-ordinated, and extremely confident, all desirable virtues for potential sportsmen. Some of these benefits may result from improved function of the corpus callosum (Luthe, 1976).

Minimal brain damage at birth, due to anoxia and haemorrhage can also impair neuro-muscular coordination in the adult. Few would recommend an exercise programme for a baby as it exercises what little muscle it has throughout its waking hours by waving its arms and legs in the air, sucking food and forcing it out, and crying loudly on every possible occasion. However neurophysiological studies (Blythe, 1978) have shown that confining a child to a baby-walker can cause it to miss out some important stages in its crawling to walking progression and can contribute to impaired coordination and psychoneuroses in later life.

Infants exercise themselves without any kind of instruction, unless forcibly confined. For their size, they are so active that one adult Olympic athlete who tried to imitate every movement that a free-range five year old made in a day, ended up completely exhausted. Infancy is an important period of muscle and bone development and they really need full scope for this intensive activity, which shapes their bones and physical skills, like balance and co-ordination for a lifetime. Habits of activity or inactivity, of posture and of over-eating, are often established before the child starts formal education at the age of five. Restrictions at this stage, such as being confined to a flat because the mother can't leave the toddler in a playground several floors below, and has to resort to pacifying it with television and sweets, can produce a fat, lethargic child which grows to become a fat lethargic adult.

\section{THE SCHOOLCHILD}

During schools years, there is usually plenty of physical activity, although games are generally competitive and, apart from the few who are able to excel, many become discouraged and leave school as spectators rather than participants. There has, however, in recent years been an encouraging growth in activities such as gymnastics and swimming, where large numbers of people can join in and reach their own enjoyable level of proficiency. This trend has been encouraged by schemes such as the graded awards of the British Amateur Gymnastics Association and the Amateur Swimming Association.

\section{THE YOUNG ADULT}

Those in their twenties and thirties usually get enough physical activity to keep reasonably fit with mating, home-building and child rearing. Also some continue their school sports such as football, tennis or squash. These are less than ideal forms of exercise because, as described later, they are erratic in intensity and competitive in nature.

\section{THE MATURE ADULT}

As the men who play them progress in their business, trade or profession, such play tends to be overtaken by work and household commitments. One expression of this progressive fall-off in participation in exercise is the large number of overweight people in their thirties seen at medical examinations for life insurance. Heart attacks are also becoming far more common in this group.

Young and not so young lovers should be encouraged by the saying of Professor Christian Barnard that for the heart "snogging is better than jogging" and we ought to take account of the fact that probably the most vigorous exercise that most of us get in adult life is taken in a horizontal position as "Sexercise".

The effects of exercise should be looked at as firstly "stretching" the sympathetic response, and then developing the parasympathetic "rebound". In this connection there is evidence that some of the benefits of exercise may in fact be due to the release of parasympathomimetic hormones such as testosterone (Reinberg et al, 1978). Although synthetic anabolic steroids have a bad image in athletics, the natural endogenous hormones can have beneficial effects both in reducing many of the coagulation factors in the blood, which may be the deciding factor in whether a person gets a coronary attack, and in reducing certain key lipids such as the 
dreaded cholesterol. (Husmann et al, 1969.) Also it may have beneficial influences on high density lipoprotein, that very fashionable carrier protein for cholesterol which keeps it out of mischief in the circulation. Exercise is one of the few factors definitely known to increase the H.D.L. levels, and as well as reducing blood pressure, resting pulse rate and lipid levels, and increasing fibrinolytic activity may be a further important mechanism by which exercise can postpone coronary disease. For the middle aged there was bad news recently when some of those who had reached the age of the "fierce soldier" were not found to be quite as fit as they used to be in the days when as an army physical training instructor, Al Murray, used to knock them into shape. A team of infantrymen were beaten on a cross country assault course by a team of women, led by the wife of one of them! Women are relatively immune from heart disease until they are over forty. Most housewives will tell you that they get plenty of exercise anyway looking after young children, keeping the home clean and shopping, and they have higher HDL levels on average than men.

\section{THE MIDDLE-AGED}

It is the middle-aged unfit male in his forties and fifties for whom exercise has the most to offer. Yet this is the very person most reluctant to take it up. Middleage spread has often caught up with him, which discourages exertion and may make him loth to appear in shorts or a bathing suit. He may also be deeply immersed in his work and not like to compete, or even exercise alongside, the younger and obviously fitter men at his office or factory, for fear of unfavourable comparisons being made.

This is understandable but sad, as it is just when diseases of the heart and circulation take their biggest toll, and together with degenerative joint conditions and breathlessness, prevent a man enjoying fully his family life and fruits of his earlier labours. It is also largely unnecessary, because a small amount of regular but vigorous exercise would prevent many of these conditions from developing and prevent joint diseases. (Fowler, 1976.)

I would like at this point to pay tribute to Al Murray, my guru in the field of exercise. This year has seen the opening of a gymnasium in the House of Commons where he is now fighting a battle to get the politicians physically fit, at least, to govern the country. I believe he has played a very large part in determining the shape of future exercise programmes in Great Britain. Turning his attention from the super fit Olympic weight-lifters, he has done yeoman service to the unfit, middle-aged and elderly individual, in defining the minimum criteria for beneficial exercise. To most people exercise does not come naturally, and they want to know how much benefit they can get in how little time and also how safely. We described in our paperback F/40: Fitness on forty minutes a week, the slogan "SAFE" which stands for Safe, Acceptable, Fitness-producing and Economic. Safety is built into the course by the type of exercise and gradual build-up under pulse control. Acceptability is essential, as the best exercise system on earth is useless unless it is used a regular basis. This is produced by having a varied series of exercises and making them easy and convenient to carry out. Fitness in the sense of a feeling of well-being, or improved strength and mobility, is the aim of most who take up exercise. Economy is provided in terms of time by the fact that these exercises only need to be carried out for two or preferably three 15 to 20 minute sessions each week. Our research at the City Gym showed how this 'condensed recipe' type of exercise could produce very big benefits for a small outlay in terms of time, space and equipment. Not only did people taking this minimal dose of exercise look and feel better, but their blood pressure and blood fat levels fell in a medically most encouraging way. (Carruthers and Murray, 1976.)

This type of exercise is sufficient to raise the oxygen uptake to $60 \%$ of maximum, which would fall within Professor Morris's definition of cardioprotective "vigorous exercise". I am not sure how Morris's later studies fit in with his earlier ones, in that in spite of the alleged beneficial effect of occupational exertion in bus conductors and postmen, after studying them with due care, as they go about their jobs in London, I have not seen them involved in what could be termed "vigorous exertion"!

The temperature at which one exercises is very important in making it safe. This may explain why in some jogging events carried out under pleasantly warm conditions, such as the recent week-end "fun-run" there was a conspicuous absence of overt coronary events in the 1600 or more competitors taking part. However where there is excessive heat, there is the danger of orthostatic hypotension, and the high adrenaline levels seen in sauna bathing. In really hot showers, there may be a similar generation of high adrenaline levels with consequent danger of arrhythmias and ectopic beats. (Taggart et al, 1972). Under cold conditions, one would expect a higher than normal level of arrhythmias because of increased noradrenaline and free fatty acid levels, a risk run by people who go out on a really cold frosty morning jogging, unless they are used to it.

While not trying to limit the undoubted pleasure that many people do get in competing when fit, there are dangers in adopting an excessively competitive attitude to sport in the unfit individual. Foe example there is the person who goes out jogging with his family and tries to show off by overtaking his son, or setting the pace too high because he feels he must be the pack leader. These 
considerations should help in orientating the public to avoid one of the worst of all sporting injuries, exercise backlash. The British experience with gymnasium exercise which is important, is that individuals should exercise at their own rate rather than in larger classes, where everybody is trying to keep up. It is also more economical in terms of time.

Also I hope that this is going to be a great year for the bicycle when after a 100 years war with the authorities, at last considerable pressure has been put on the politicians to provide safe acceptable cycling facilities. The British Cycling Bureau is releasing a digest of 10 reports called 'Cycling, the Healthy Alternative', where it points out just how much benefit could be gained by encouraging people to balance their biochemistry on bicycles. This is an important form of exercise which people will take if they can commute by bicycle or use their bicycles over weekends, and could if widely accepted to coin a phrase, cut heart attacks rates "at a stroke". Sixty British M.P.'s led by Sir George Young are promoting this form of transport by forming a Parliamentary cycling lobby.

Working at the Institute of Psychiatry I now tend to take more seriously the psychological benefits of exercise. There are a large number of drugs on the market which aim to induce tranquility and elevate mood. A lot of these act by raising brain amine levels. Exercise is a very good non-drug, non-doctor way of raising brain amine levels, particularly in relation to the noradrenaline level which stimulates pleasure centres in the hypothalamus, and so improves the mood. Carruthers, 1977. Practical evidence has come forward recently from Dr. John Greist, a psychiatrist who has demonstrated on a controlled trial basis that a course of jogging can act as a better anti-depressant than traditional psychotherapy. (Greist et al, 1978).

\section{THE ELDERLY}

As with the middle-aged, the "shrunk-shanks", and more importantly the deteriorating cardio-vascular system of the elderly, can be considerably improved by a moderate amount of carefully applied exercise. This was dramatically demonstrated in a group of retired people doing a 2 months course of F/40 type of exercise in the B.B.C.'s 60-70-80 show. Not only did they feel and look better, but the conventional medical indices of circulatory fitness such as resting pulse rate, blood pressure, lipid and fibrinogen levels all showed equal marked improvement. This was a dramatic demonstration, which has since been made into a separate film for the Pre-retirement Association, of the ability of exercise to add life to years, as well as years to life.

\section{THE OLD}

What you don't use, you lose. This is most clearly seen in old people who are suddenly confined to bed, for example by a fractured hip. Both mental function and many physical systems deteriorate rapidly and this fully justifies the skilled efforts of the physiotherapy profession, of which this country is rightly proud, to get them on their feet again.

In conclusion I would like to mention an organisation started just over a year ago, called the European Organisation for the Control of Circulatory Diseases. Its President, Dr. Jens Moller in Copenhagen, has created this organisation to get political muscle to back up medical thinking in this field in a very practical sense. He makes the point that if you want to talk to Politicians you largely have to do it in money terms. For this purpose he has collected a considerable amount of evidence particularly from the Federal Republic of West Germany, where a cost-effectiveness study was carried out in providing exercise facilities as a method of preventing cardio-vascular disease. They estimate that they got a three-fold return on the amount of money that they had laid out in terms of reduced sickness absence, direct medical expenses and other costs such as sickness benefits and retirement pay. In short exercise makes financial as well as medical sense!

\section{REFERENCES}

Blyth, P. 1978. Minimal brain damage and the treatment of psychoneuroses. Journal of Psychosomatic Research, 22, 242.

Carruthers, M. and Murray, A. 1976. F/40: Fitness on forty minutes a week. Futura books, London.

Carruthers, M. 1977. The Chemical anatomy of stress, edited by Kielholz, P. in "Beta-blockers and the central nervous system", Huber Berne.

Enger, S. C., Herbjornsen, K., Erikssen and Fretland, A., 19 . HDL and physical activity: the influence of physical exercise, age and smoking on HDL cholesterol and the HDL-/total cholesterol ratio.

Fowler, A. W. 1976. In “Cycling the healthy alternative", published by The British Cycling Bureau, 1978. 
Greist, J. et al., 1978. Running through your mind, Journal of Psychosomatic Research, $22,259$.

Husmann, F., Haug, H., Suchan, P. and Cross, W. 1969. The effect of methyl testosterone on serum lipids, Klin.Wschr. 47, 411 .

Leboyer, F. 1974. Birth without violence. Wildwood Press, London.

Luthe, W. 1976. Creativity mobilisation technique, Gruneard Station, New York.

Reinberg, A. and Lagogney, M. 1978. Circadian and circaannual rhythms in plasma hormones and other variables of five healthy young human males. Acta Endocrinologica, 88, 417.

Taggart, P., Parkinson, P. and Carruthers, M. 1972. Cardiac responses to thermal physical and emotional stress. B.M.J. 3 71. 